\title{
HUBUNGAN KELELAHAN DAN TINGKAT STRES MAHASISWA SEMESTER AKHIR FAKULTAS Y UNIVERSITAS X DI BANYUWANGI
}

\author{
Relationship Between Fatigue and Stress Level in Final Students of Faculty Y University X \\ in Banyuwangi
}

\author{
Arini Khoirunisa ${ }^{1}$, Endang Dwiyanti ${ }^{2}$ \\ ${ }^{1}$ Departemen Keselamatan dan Kesehatan Kerja, Fakultas Kesehatan Masyarakat, PSDKU Universitas Airlangga di \\ Banyuwangi, Banyuwangi, Indonesia \\ ${ }^{2}$ Departemen Keselamatan dan Kesehatan Kerja, Fakultas Kesehatan Masyarakat, Universitas Airlangga, Surabaya, \\ Indonesia
}

\begin{tabular}{l}
\hline ARTICLE \\
INFO \\
Article History: \\
Received: \\
July, $1^{\text {th }}, 2021$ \\
Revised: \\
From, July, $2^{\text {h }}$, \\
2021 \\
Accepted: \\
August, 05 ${ }^{\text {th }}$, \\
2021 \\
Published \\
online October, \\
$11^{\text {th }}, 2021$
\end{tabular}

\begin{abstract}
Final semester students have a heavier study load than early-level student that can make fatigue trigger wich leads to stress. This study aimed to find out strenght relation between fatigue and stress level in the final semester students of Faculty $Y$ University $X$ in Banyuwangi. This study used crosssectional study and respondents were the final semester students of Faculty $Y$ University $X$ in Banyuwangi amounting 41 students. Data were collected through distribution of online questionnaire that fatigue level was measured by Subjective Self Rating questionnaire. While level of stress was measured by the General Health Questionnaire. The relationship strength was obtained with contingency coefficient to determine the strength of the relationship between the two variables with ordinal data category and the total population methode and the result of contingency coefficient value is 0,688 wich stated that there was a strong relationship between fatigue and stress levels. Most of the final semester students have moderate stress level that is $70.7 \%$.The conclusion of the study shows there is a strong relationship between fatigue and stress level in final semester students of Faculty Y University X in Banyuwangi. It is hope that final semester students have rest time to avoid fatigue and stress.

Keywords: fatigue level, stress level, final semester student
\end{abstract}




\section{PENDAHULUAN}

Sehat merupakan keadaan terbebas dari segala penyakit baik secara fisik, mental dan juga kondisi sejahtera pada kognitif, sosial dan emosional (World Health Organization, 2020). Kesehatan menjadi investasi penting bagi negara dengan salah satu indikator pembangunan kesehatan berkelanjutan yakni penekanan dan target pada kesehatan mental (World Health Organization, 2017). Sehat secara mental adalah keadaan sejahtera pada individu dimana seseorang sadar akan kemampuannya dan dapat mengatasi permasalahan hidup yang normal, mampu bekerja secara produktif dan memberikan kontribusi kepada sosial sehingga seseorang dengan gangguan kesehatan mental akan sulit berpikir, menjalani kesehariannya dan mengekspresikan dirinya di kehidupan sosial (World Health Organization, 2017). Oleh karena itu, kesehatan mental menjadi aspek penting seseorang dalam menjalankan kehidupan sehari-hari.

Salah satu gangguan kesehatan mental yang sering terjadi adalah stres. Seseorang dengan tekanan dan tegangan melebihi kemampuannya seringkali sulit menemukan jalan keluar dari masalah yang sedang dihadapinya, sehingga dapat memicu stres (Gamayanti et al., 2018). Stres dapat diartikan sebagai situasi yang dialami oleh individu akibat dari ketegangan yang berlebihan yang tidak dapat ditangani melebihi kemampuan dirinya. Stres terjadi karena adanya ketegangan dan tekanan, salah satunya adalah tekanan akademik yang menuntut mahasiswa akhir (Puspitha et al., 2018). Menurut Lahey dalam (Gamayanti et al., 2018) tekanan atau pressure merupakan salah satu sumber stres yang dapat menimbulkan konflik antara tuntutan dan kemampuan karena adanya keterpaksaan dalam diri seseorang. Sehingga, tekanan berlebih akan menciptakan ketimpangan antara beban dan kemampuan individu, dimana pada titik tertentu akan menciptakan respon negatif yang dinamakan stres.

Stres sering terjadi pada manusia dan harus menjadi perhatian bagi semua orang. Akan tetapi sebagian besar dunia tidak semua negara menganggap kesehatan mental menjadi penting seperti kesehatan fisik. Terlebih faktor masalah kesehatan secara fisik lebih terlihat dibandingkan secara psikologis. Secara global, pada tahun 2019 total penduduk yang mengalami depresi dan stres adalah 264 juta jiwa (World Health Organization, 2019). Prevalensi kejadian stres menurut World Health Organization adalah menjadi peringkat 2 di dunia pada tahun 2020 Sedangkan pada mahasiswa di Asia didapatkan kejadian stres sebesar 39,6$61,3 \%$ dengan angka lebih dari 350 juta penduduk (Koochaki et al., 2011). Institute for Health and Evaluation (IHME) mencatat bahwa gangguan mental menyumbang kontribusi beban penyakit sebesar 13,4\% dan menjadi penyebab kecacatan terbesar (Pusat Data dan Informasi Kementrian Kesehatan RI, 2019). Data Riskesdas 2018 menunjukkan prevalensi gangguan mental emosional pada penduduk 15 tahun keatas di Jawa Timur sebesar 6,8\% atau sekitar 111 juta jiwa (Kementerian Kesehatan RI, 2018). Sedangkan di Banyuwangi, prevalensi gangguan mental emosional penduduk di atas 15 tahun sebesar $11,77 \%$ atau sebanyak 3.042 jiwa dari total penduduk Banyuwangi 1.735.845 jiwa ((Kementerian Kesehatan RI, 2018). Data tersebut menunjukkan bahwa masalahan gangguan kesehatan mental masih menjadi masalah serius yang harus segera ditangani.

Stres dapat terjadi pada siapa saja, salah satunya pada mahasiswa. Mahasiswa semester akhir mempunyai tanggung jawab untuk membuat skripsi sebagai tugas akhirnya. Tuntutan menyelesaikan skripsi sebagai tugas akhir, dapat menjadi penyebab stres pada mahasiswa semester akhir (Tri, 2019). Penelitian yang dilakukan pada 330 mahasiswa farmasi semester akhir di Indonesia pada bulan Desember tahun 2019 menunjukkan bahwa $87 \%$ mengalami 
stres dalam 6 bulan terakhir (Kristina et al., 2020). Penelitian mengenai respon stres yang dilakukan pada tahun 2020 terhadap 110 mahasiswa jurusan fisioterapi, menunjukkan bahwa kecemasan akan lebih berat dirasakan pada mahasiswa tahun terakhir (Ramírez-Adrados et al., 2020). Penelitian tersebut sejalan dengan hasil penelitian yang dilakukan pada tahun 2013 terhadap mahasiswa keperawatan semester akhir, ditemukan bahwa mahasiswa semester akhir lebih rentan mengalami kecemasan karena semakin banyaknya beban dan tanggung jawab akademik (Moreira \& Furegato, 2013). Hal ini terkait pada tugas akhir atau skripsi serta kecemasan pada prospek pasar kerja yang akan mereka hadapi dalam waktu dekat. Pasar kerja memberikan tuntutan dan persaingan yang ketat mengenai profesionalitas dan kualifikasi tertentu pada calon pekerja, terlebih pada lulusan baru (Moreira \& Furegato, 2013)

Stres diungkapkan juga sebagai kondisi yang disebabkan oleh ketidaksesuaian antara situasi yang diinginkan dengan keadaan biologis, psikologis atau sistem sosial dari individu (Seaward, 2018). Keadaan yang tidak sesuai dapat dipengaruhi oleh banyak faktor, salah satunya kelelahan. Pada penelitian yang dilakukan oleh pada 262 responden mahasiswa Fakultas Kedokteran Universitas Udayana didapatkan hasil bahwa kelelahan berhubungan dengan stres, sebanyak $56,9 \%$ dari total responden mengalami stres tingkat sedang (Nathania et al., 2019). Hal ini sejalan dengan penelitian yang dilakukan Doerr et al. (2015) pada 50 mahasiswa Fakultas Psikologi di Jerman menunjukkan adanya hubungan antara kelelahan dan stres akut. Penelitian Johanna menjelaskan bahwa ada hubungan timbal balik bersifat negatif antara kelelahan dan stres yang keduanya saling memengaruhi.

Kelelahan memegang peran penting untuk memunculkan stres (Doerr et al., 2015). Seseorang yang lelah rentan menjadikan dirinya menjadi stres.
Penelitian yang dilakukan pada tahun 2018 dengan sasaran 100 mahasiswa STIE menunjukkan hasil adanya pengaruh positif antara kelelahan dengan kualitas tidur (Amri \& Putra, 2018). Hasil tersebut sejalan dengan penelitian yang dilakukan oleh Tri dan Dwi (2019) pada 133 mahasiswa semester akhir STIKES menunjukkan bahwa seseorang dengan gangguan tidur memiliki hubungan yang signifikan dengan stres. Penelitian yang dilakukan Kristina, dkk (2020) pada mahasiswa farmasi di Indonesia juga melaporkan adanya stresor akdemik yang signifikan berhubungan dengan tingkat stres. Tanggungjawab penyelesaian skripsi dapat menjadi salah satu stresor akdemik mahasiswa. Mahasiswa semester akhir memiliki tanggung jawab yang memungkinkan mereka mengalami kelelahan yang berujung pada stres. Sehingga perlu dilakukan penelitian ini untuk mengetahui hubungan tingkat kelelahan dan stres pada mahasiswa semester akhir. Tujuan penelitian ini adalah untuk mengetahui kuat hubungan kelelahan dengan tingkat stres pada mahasiswa semester akhir Fakultas Y Univexrsitas X di Banyuwangi.

\section{METODE PENELITIAN}

Desain penelitian ini adalah penelitian kuantitatif dengan pendekatan cross sectional yaitu observasi pada variabel dilakukan pada satu waktu tertentu. Penelitian ini dilakukan dengan menyebarkan kuesioner online pada tanggal 24 hingga 27 Mei 2021 dengan populasi penelitian adalah Mahasiswa semester akhir Fakultas Y Universitas X di Banyuwangi dengan jumlah populasi sebanyak 41 Mahasiswa. Sebelum melakukan pengisian data, responden telah mendapatkan penjelasan penelitian dan lembar persetujuan apakah bersedia menjadi salah satu respoden dalam penelitian ini. Pada penelitian ini terdapat dua variabel yaitu variabel independen dan dependen. Variabel independen dalam penelitian ini adalah tingkat kelelahan, sedangkan 
variabel dependen pada penelitian ini adalah tingkat stres. Tingkat kelelahan diukur dengan kuesioner General Health Questionnaire-12 (GHQ-12) yang dikembangkan oleh David Goldberg pada tahun 1974 dengan 12 pertanyaan terdiri dari 6 aitem dimensi distres psikologis dan 6 aitem disfungsi sosial. Kuesioner ini diubah dalam bentuk bahasa Indonesia dan hasil uji validitasnya pada skala likert dilihat beradasar nilai sensitifitas dan spesifisitas 0,81 dan 0,62 , sedangkan reliabilitasnya menunjukkan hasil 0,86 sehingga dapat dikatakan kusesioner GHQ12 reliabel (Primasari \& Hidayat, 2016). Metode skoring pada kuesioner GHQ-12 menggunakan skala likert dengan nilai terendah 0 dan nilai tertinggi 3. Sedangkan tingkat kelelahan diukur secara subyektif menggunakan kuesioner Subjective Self Rating Test (SRRT) dari Industrial Fatigue Research Committee (IFRC) yang mulai dikenalkan pada pada tahun 1969 kemudian dikembangkan lagi dengan metode skoring skala likert (Ramdan, 2018). Kuesioner SRRT-IFRC berisi 30 aitem mencakup gejala kelelahan umum (Tarwaka dalam Sari, 2019). Adapun pengkategorian tingkat kelelahan dan stres dibagi menjadi 3 yakni berat, sedang dan ringan didasarkan pada distribusi data (Santoso, 2001 dalam Hasanah, 2019). Skor GHQ-12 dibagi menjadi 3 kategori berdasarkan mean dan standar deviasi yaitu berat (lebih dari 22), sedang (antara 10 hingga 22) dan ringan (kurang dari 10). Sedangkan skor SRRTIFRC dikategorikan menjadi berat (lebih dari 80), sedang (antara 54 hingga 80), dan ringan (kurang dari 54). Pengolahan data dilakukan melalui program SPSS versi 21 dan dianalisis dengan tabel tabulasi silang dan narasi. Kuat hubungan antara variabel dependen dan independen diukur menggunakan uji contingency coefficient (c) karena pada penelitian bentuk data yang digunakan adalah ordinal dan menggunakan metode total populasi.
Tabel 1. Nilai Contingency Coefficient

\begin{tabular}{|l|l|}
\hline $\begin{array}{l}\text { Nilai contingency } \\
\text { coefficient } \text { (c) }\end{array}$ & Kuat Hubungan \\
\hline $0,000-0,199$ & Sangat rendah \\
\hline $0,200-3,999$ & Rendah \\
\hline $0,400-0,599$ & Sedang \\
\hline $0,600-0,799$ & Kuat \\
\hline $0,800-1,000$ & Sangat Kuat \\
\hline
\end{tabular}

Sumber: Sugiyono (2015)

\section{HASIL}

Penyajian data penelitian meliputi data umum dan data khusus. Data umum berupa jenis kelamin dan usia serta data khusus berupa tingkat kelelahan dan stres.

Tabel 2. Karakteristik Responden

\begin{tabular}{|l|r|r|}
\hline $\begin{array}{c}\text { Karakteristik } \\
\text { Responden }\end{array}$ & Frekuensi & $\begin{array}{c}\text { Persentase } \\
(\%)\end{array}$ \\
\hline Jenis Kelamin \\
\hline Laki-laki & 6 & 14,6 \\
\hline Perempuan & 35 & 85,3 \\
\hline Usia \\
\hline 20 & 1 & 2,4 \\
\hline 21 & 12 & 29,2 \\
\hline 22 & 23 & 56,1 \\
\hline 23 & 4 & 9,7 \\
\hline 24 & 1 & 2,4 \\
\hline Tingkat Kelelahan \\
\hline Ringan & 7 & 17,0 \\
\hline Sedang & 25 & 60,9 \\
\hline Berat & 9 & 21,4 \\
\hline Tingkat Stres & \multicolumn{2}{|}{} \\
\hline Ringan & 4 & 9,7 \\
\hline Sedang & 29 & 70,7 \\
\hline Berat & 8 & 19,5 \\
\hline
\end{tabular}

Sumber: Data primer, 2021

Tabel 2. Menggambarkan karakteristik responden yang terdiri dari 41 responden. Responden didominasi oleh jenis kelamin perempuan sebanyak 35 orang $(85,4 \%)$. Responden paling banyak berusia 22 tahun sebesar 56,1\% (23 dari 41 orang) dan sisanya berusia 20, 21, 23 dan 24 tahun. Tabel di atas menunjukkan bahwa banyak mahasiswa yang mengalami kelelahan sedang yakni sebanyak 25 orang 
(61\%) dan kelelahan ringan sedikit dialami mahasiswa semester akhir yakni sejumlah 7 orang (17\%). Sedangkan pada tingkat stres, mahasiswa semester akhir banyak mengalami stres tingkat sedang sebanyak 29 orang $(70,7 \%)$ dan hanya sedikit mahasiswa yang mengalami stres ringan yakni sejumlah 4 orang $(9,8 \%)$.

Hasil analisis bivariat antara variabel independen dan dependen disajikan pada tabulasi sebagai berikut: didominasi perempuan sebanyak 35 responden $(85,4 \%)$. Secara umum diperoleh bahwa dari 41 responden didapatkan 7 orang mengalami kelelahan ringan, 25 mengalami kelelahan sedang dan 9 orang mengalami kelelahan berat. Sedangkan pada tingkat stres, 4 orang mengalami stres ringan, 29 orang mengalami stres sedang, dan 8 mengalami stres berat. Hasil analisis data tersebut didapatkan berdasarkan kuesioner Subjective Self Rating Test

Tabel 3. Tabulasi silang hubungan Kelelahan dengan Tingkat Stres Mahasiswa Semester Akhir Fakultas Y Universitas X di Banyuwangi.

\begin{tabular}{|c|c|c|c|c|c|c|c|}
\hline \multirow[t]{3}{*}{ Kelelahan } & \multicolumn{6}{|c|}{ Tingkat Stres } & \multirow{2}{*}{$\begin{array}{l}\text { Nilai Koefisien } \\
\text { Kontingensi (c) }\end{array}$} \\
\hline & \multicolumn{2}{|c|}{ Ringan } & \multicolumn{2}{|c|}{ Sedang } & \multicolumn{2}{|c|}{ Berat } & \\
\hline & $\mathbf{n}$ & $\%$ & $\mathbf{n}$ & $\%$ & $\mathbf{n}$ & $\%$ & \multirow{5}{*}{0,688} \\
\hline Ringan & 4 & 100,0 & 3 & 10,3 & 0 & 0,0 & \\
\hline Sedang & 0 & 0,0 & 23 & 79,3 & 2 & 25,0 & \\
\hline Berat & 0 & 0,0 & 3 & 10,3 & 6 & 75,0 & \\
\hline Total & 4 & 9,7 & 29 & 70,7 & 8 & 19,5 & \\
\hline
\end{tabular}

Sumber: Data primer, 2021

Hasil analisis bivariat berdasarkan Tabel 3, menunjukkan bahwa 8 mahasiswa dengan stres berat 2 mahasiswa atau sebasar 25\% memiliki tingkat kelelahan sedang dan 6 atau sebesar $75 \%$ dengan kelelahan berat. Selanjutnya, 29 mahasiswa yang mengalami stres sedang, 3 mahasiswa atau sebesar $33,3 \%$ orang dengan kelelahan ringan, 23 mahasiswa atau sebesar 79,3\% dengan kelelahan sedang dan 3 mahasiswa atau sebesar 33,3\% dengan kelelahan berat. Sedangkan 4 mahasiswa dengan tingkat stres ringan, semuanya atau $100 \%$ memiliki tingkat kelelahan ringan. Berdasarkan hasil uji kuat hubungan menggunakan contingency coefficient (c), menunjukkan bahwa nilai $(c)=0,688$, yang berarti bahwa terdapat hubungan yang kuat antara kelelahan dengan tingkat stres ringan, sedang, dan berat pada Mahasiswa Semester Akhir Fakultas Y Universitas X di Banyuwangi

\section{PEMBAHASAN}

Berdasarkan hasil penelitian, didapatkan dari jenis kelamin responden
(SSRT) untuk tingkat kelelahan dan General Health Questionnaire (GHQ-12) dengan 3 pengkategorian nilai yakni ringan, sedang, dan berat. Pengkategorian hasil data ini juga dilakukan oleh Putri \& Tualeka (2014) pada penelitian hubungan stres kerja dengan produktivitas kerja. Pengkategorian ini didasarkan pada distribusi data dengan pendekatan mean dan standar deviasi (SD) (Hasanah, 2019).

Jumlah responden yang mengalami kelelahan tingkat sedang lebih banyak yakni sebesar $60,9 \%$ (25 dari 41 orang) daripada tingkat ringan atau berat. Hal ini sejalan dengan penelitian yang dilakukan Nathania, dkk (2019) pada 262 mahasiswa Fakultas Kedokteran Universitas Udayana yang melaporkan banyak mahasiswa mengalami kelelahan sedang sebesar 56,9\% kemudian dilanjut dengan kelelahan rendah sebesar 29,8\%. Mahasiswa semester akhir memiliki beban yang lebih tinggi dan cenderung mengalami kelelahan secara fisik, emosional maupun mental (Ambarwati, dkk., 2019). Hal tersebut disebabkan banyaknya tuntutan yang harus diselesaikan dalam jangka waktu tertentu, 
salah satunya penyelesaian skripsi sebagai tugas akhir.

Sedangkan pada tingkat stres, jumlah mahasiswa lebih banyak mengalami stres tingkat sedang yakni sebesar 70,7\% (29 dari 41 orang) dan dilanjutkan stres tingkat berat yakni sebesar 19,5\% (8 dari 41 orang). Hasil tersebut didukung oleh penelitian Ambarwati, dkk (2019) yang dilakukan tahun 2017 pada 101 mahasiswa semester akhir, menunjukkan 47,5\% mahasiswa mengalami stres dengan hasil tertinggi 57,4\% mahasiswa mengalami stres sedang. Stres yang dialami mahasiswa semester akhir cenderung sering terjadi karena mereka dalam proses pengerjaan skripsi atau tugas akhir yang membutuhkan ketelitian tinggi, memakan waktu dan tenaga dan kemampuan internal (Darmono dalam Anwar, 2016). Keberadaan stres yang timbul akibat adanya kelelahan dijelaskan oleh Selye dengan model respon General Adaptation Syndrome (GAS) bahwa terdapat tiga faktor yang terlibat dalam merespon stres yakni saraf, ketahanan tubuh atau imun, dan sistemn endokrin (Selye dalam Krajewski, 2017). Hal ini dijelaskan terdapat dua respon dalam tubuh yang dilakukan oleh sistem pertahanan yakni menghadapinya atau meninggalkan ancaman atau stressor. Respon perlawanan atas stressor yang terjadi dalam tubuh menyebabkan pelepasan hormon kortisol yang apabila keadaan tubuh lelah tidak dapat mengambil respon tersebut. Sehingga seseorang yang lelah akan cenderung mengalami stres karena hormon kortisol tidak dapat dilepaskan, sedangkan paparan stressor masih berlanjut (Seaward, 2018).

Hasil tabulasi silang antara dua variabel, menunjukkan bahwa adanya huhungan kuat antara kelelahan dan tingkat stres pada Mahasiswa Semester Akhir Fakultas Y Universitas X di Banyuwangi. Hasil tersebut didapatkan dengan uji kuat hubungan menggunakan koefisien kontingensi. Didapatkan hasil koefisien kontingensi sebesar 0,688 menunjukkan adanya hubungan kuat antara kelelahan dan tingkat stres pada Mahasiswa Semester Akhir Fakultas $\mathrm{Y}$ Universitas $\mathrm{X}$ di Banyuwangi. Secara umum, dari 41 responden didapatkan hasil bahwa responden dengan kelelahan berat $(70,7 \%)$ cenderung mengalami stres berat sebanyak $66,7 \%$ (6 dari 9 orang). Sedangkan mahasiswa dengan kelelahan ringan sebanyak 17\% (7 dari 41 orang) cenderung mengalami stres ringan (4 dari 7 orang) dan sedang (3 dari 7 orang). Hal ini sejalan dengan penelitian yang dilakukan oleh Doerr, dkk (2015) pada mahasiswa Fakultas Psikologi Jerman, bahwa adanya hubungan kelelahan dengan stres. Penelitian tersebut mengungkapkan bahwa pada situasi ujian kelelahan akan meningkat dan ini bersifat positif. Selain itu, penelitian Doerr, dkk (2015) mengungkapkan bahwa situasi ujian menyebabkan ketegangan yang menjadikan tingkat kelelahan semakin berat (Doerr et al., 2015). Adanya ketegangan yang meningkatkan kelelahan dinilai sebagai stressor atau pemicu stres.

Mahasiswa semester akhir merupakan mahasiswa dengan tahun terakhir di perkuliahan. Mereka memiliki tuntutan dan tanggungjawab yang berat, yakni menyelesaikan perkuliahan dengan tenggat waktu tertentu. Hal ini akan menjadikan ketegangan dan kecemasan yang berujung pada stres. Selain itu, beban belajar yang semakin banyak pada mahasiswa semester akhir menjadikannya seringkali kelelahan yang berujung pula pada kondisi stres. Hal tersebut sejalan dengan penelitian yang dilakukan oleh Nathania, dkk (2019) dengan 262 sampel, didapatkan nilai signifikansi 0.000 yang menandakan adanya pengaruh antara stres dengan kelelahan. Kondisi stres akan parah bila seseorang mengalami kelelahan karena kondisi lelah menyebabkan penurunan fungsi biologis seseorang. Selain itu, sistem stres yang selalu aktif menyebabkan tubuh lelah (Kocalevent et al., 2011).

Selain itu dikemukakan bahwa terdapat mediator antara kelelahan dan stres yakni kualitas tidur dan ketegangan. Penelitian yang dilakukan oleh Krajewski 
(2017) menemukan kualitas buruk dan gangguan tidur memiliki pengaruh pada kelelahan. Mahasiswa semester akhir mempunyai tanggungjawab untuk menyelesaikan kuliahnya dengan tenggat waktu yang tidak lama. Selain itu, mahasiswa semester akhir memiliki tugas menyelesaikan skripsi atau tugas akhir sebagai syarat kelulusannya. Hal ini tidak jarang menjadikan mahasiswa semester akhir menemui kesulitan dan kendala seperti sulitnya bertemu dosen pembimbing, mencari literatur dan referensi, atau lingkungan yang tidak mendukung (Fadila dalam Nana, 2018) Kendala-kendala tersebut dapat membuat proses penyelesaian skripsi berjalan lama sehingga menjadikan kelelahan yang berujung pada stres (Mujiyah dalam Nana, 2018). Selain itu, mahasiswa semester akhir seringkali mengalami kekurangan tidur dan istirahat untuk menyelesaikan tugas akhir atau skripsinya. Hal tersebut didukung dengan penelitian Tri (2019) yang melaporkan bahwa 96,2\% mahasiswa yang stres memiliki kualitas tidur buruk. Sehingga kualitas tidur dapat menjadi faktor penghubung antara kelelahan dan terjadinya stres. Seseorang dengan kualitas tidur yang baik akan menurunkan terjadinya risiko stres. Antara kelelahan dan kualitas tidur, keduanya saling berpengaruh terhadap stres (Kocalevent et al., 2011). Keadaan tersebut perlu respon segera dengan menghilangkan faktor penyebab kelelahan seperti menjaga kualitas tidur, pengaturan istirahat dan manajemen stres.

Peneliti menyadari masih terdapat kekurangan yang menjadi keterbatasan dalam penelitian. Salah satunya adalah jumlah responden yang diteliti hanya 41 orang yang belum cukup menggambarkan keadaan yang seseungguhnya. Diharapkan pada penelitian selanjutnya untuk mempertimbangkan jumlah responden yang akan diteliti.

\section{SIMPULAN DAN SARAN}

Berdasarkan hasil penelitian dapat disimpulkan bahwa terdapat hubungan kuat antara kelelahan dengan tingkat stres mahasiswa semester akhir. Mahasiswa dengan kelelahan berat akan cenderung mengalami stres. Sebaiknya mashasiswa akhir menjaga dirinya dari kelelahan saat melakukan proses skripsi agar tidak mengalami stres. Kelelahan tersebut dapat dicegah dengan kualitas tidur yang cukup. Selain itu, bagi peneliti selanjutnya hendaknya memperhatikan keterbatasan dalam penelitian ini dengan mempertimbangkan jumlah responden yang akan diteliti.

\section{UCAPAN TERIMA KASIH}

Puji syukur atas kehadirat Allah SWT atas kehendak-Nya, penulis dapat menyelesaikan artikel ini hingga akhir. Terimakasih kepada ibu dosen pembimbing yang selalu mendukung serta teman-teman yang turut membantu dalam penyelesaian artikel ini.

\section{REFERENSI}

Ambarwati, P. D., Pinilih, S. S., \& Astuti, R. T. (2019). Gambaran Tingkat Stres Mahasiswa. Jurnal Keperawatan Jiwa, 5(1), 40. https://doi.org/10.26714/jkj.5.1.201 7.40-47

Amri, \& Putra, M. D. (2018). Pengaruh Konflik Kerja-Kuliah Mingguan Terhadap Kelelahan Dengan Kualitas Tidur Sebagai Pemediasi Pada Mahasiswa Dan Mahasiswi STIE Kebangsaan di Bireuen. Jurnal Ilmiah Mahasiswa Ekonomi Manajemen, 3(2), 136-147.

Anwar, A. F. (2016). Gambaran Derajat Stres dan Kualitas Belajar pada Mahasiswa Tingkat Awal dan Mahasiswa Tingkat Akhir Program Studi DIII Kebidanan UIN Alaudin Makassar Tahun 2016. (Karya Tulis 
Ilmiah D3 Kebidanan Fakultas Kedokteran Dan Ilmu Kesehatan UIN Alaudin Makassar, 2016), 119.

Doerr, J. M., Ditzen, B., Strahler, J., Linnemann, A., Ziemek, J., Skoluda, N., Hoppmann, C. A., \& Nater, U. M. (2015). Reciprocal relationship between acute stress and acute fatigue in everyday life in a sample of university students. Biological Psychology, 110, 42-49. https://doi.org/10.1016/j.biopsycho. 2015.06.009

Gamayanti, W., Mahardianisa, M., \& Syafei, I. (2018). Self Disclosure dan Tingkat Stres pada Mahasiswa yang sedang Mengerjakan Skripsi. Psympathic: Jurnal Ilmiah Psikologi, 5(1), 115-130. https://doi.org/10.15575/psy.v5i1.2 282

Hasanah, M. (2019). PEMILIHAN JUMLAH KATEGORI TERBAIK PADA MODEL ROUGHREGRESI BERDASARKAN MEAN SQUARE ERROR. (Tugas Akhir Fakultas Sains Dan Teknologi UIN Sultan Syarif Kasim Riau, 2019).

Kementerian Kesehatan RI. (2018). Laporan Riskesdas 2018. Laporan Nasional Riskesdas 2018, 53(9), 154-165.

Kocalevent, R. D., Hinz, A., Brähler, E., \& Klapp, B. F. (2011). Determinants of fatigue and stress. Bio Medical Journal, 4, 0-4. https://doi.org/10.1186/1756-05004-238

Koochaki, G. M., Charkazi, A., Hasanzadeh, A., Saedani, M., Qorbani, M., \& Marjani, A. (2011). Prevalence of stress among Iranian medical students: A questionnaire survey. Eastern Mediterranean Health Journal, 17(7), 593-598. https://doi.org/10.26719/2011.17.7. 593

Krajewski, K. (2017). The Relationship
Between Stress and Exercise With Fatigue And Sleep Quality As Mediating Variables. (Thesis Degree of Psychology University of Michigan, 2017).

Kristina, S. A., Widayanti, A. W., \& Sari, I. P. (2020). Investigating perceived stress among final-year pharmacy students in Indonesia. International Journal of Pharmaceutical Research, 12(2), 439-444. https://doi.org/10.31838/ijpr/2020.1 2.02.0067

Moreira, D. P., \& Furegato, A. R. F. (2013). Stress and depression among students of the last semester in two nursing courses. Revista LatinoAmericana de Enfermagem Journal, 21(spe), https://doi.org/10.1590/s010411692013000700020

Nana. (2018). KESULITAN MAHASISWA SEMESTER AKHIR DALAM MENYUSUN SKRIPSI. (Skripsi Fakultas Tarbiyah dan Keguruan Universitas Islam Negri Sultan Thaha Saifuddin Jambi, 2018).

Nathania, A., Krisna Dinata, I. M., \& Adiartha Griadhi, I. P. (2019). Hubungan stres terhadap kelelahan pada mahasiswa Fakultas Kedokteran Universitas Udayana. Intisari Sains Medis, 10(1), 134138.

https://doi.org/10.15562/ism.v10i1. 400

Primasari, I., \& Hidayat, R. (2016). General Health Qquestionnaire-12 (GHQ12) sebagai Instrumen Skrinning Gangguan Penyesuaian. Jurnal Psikologi, 43(2), 121. https://doi.org/10.22146/jpsi.9155

Pusat Data dan Informasi Kementrian Kesehatan RI. (2019). Situasi Kesehatan Jiwa DI Indonesia. In InfoDATIN (p. 12).

Puspitha, F. C., Sari, M. I., \& Oktaria, D. (2018). Hubungan Stres Terhadap Motivasi Belajar Mahasiswa 
Tingkat Pertama Fakultas Kedokteran Universitas Lampung The Relation Between Stress and Learning Motivation of First Year Medical Student in Medical Faculty Of Lampung University. Medical Journal of Lampung University, 7(3), 24-33.

Putri, G. W. Y., \& Tualeka, A. R. (2014). Hubungan Antara Stres Kerja dengan Tingkat Produktivitas Tenaga Kerja di CV. "X." The Indonesian Journal of Occupational Safety, Health and Environment (IJOSH), 1(1), 144-154.

Ramdan, I. M. (2018). Kelelahan Kerja pada Penenun Tradisional Sarung Samarinda (Pertama, pp. 6-7). Uwais.

Ramírez-Adrados, A., Fernández-Martínez, S., Martínez-Pascual, B., Gonzalezde-Ramos, C., Fernández-Elías, V. E., \& Clemente-Suárez, V. J. (2020). Psychophysiological stress response of physiotherapy last year students in his final degree dissertation. Physiology and Behavior, 222(May), 112928. https://doi.org/10.1016/j.physbeh.2 020.112928

RI, K. K. (2018). LAPORAN PROVINSI JAWA TIMUR RISKESDAS 2018.

Sari, A. M. (2019). Hubungan Beban Kerja Fisik, Mental Dan Perubahan Fisiologis Dengan Kelelahan Pada Pekerja Buruh Angkut Di Pt Semen Bosowa Banyuwangi. (Skripsi Program Sarjana, Universitas Airlangga, 2019).

Seaward, B. L. (2018). Managing stress. In Nancy (Ed.), Jones and Barlett Learning. Cathy L. Esperti.

Tri, D. (2019). Hubungan stres dengan kualitas tidur pada mahasiswa tingkat akhir. EDU MASDA JOURNAL, 3(2).

World Health Organization. (2017). Fact sheet on Sustainable Development Goals (SDGs): health targets. World Health Organization, 3, 1-8.
World Health Organization. (2020). The new European policy for health Health 2020. EUR/RC61/Inf.Doc./4, 6(September), 107. 